\title{
The methodology of the vibrational separating machines bearing structure rigidity optimization and the actuating mechanism parts dynamic forces determination
}

\author{
Valeriy Piven ${ }^{1, *}$, Olga Umanskaya ${ }^{2}$ \\ ${ }^{1}$ Department of machines and equipment of oil and gas industry, Tyumen Industrial University, \\ Tyumen, Russia \\ ${ }^{2}$ Department of applied mechanics, Tyumen Industrial University, Tyumen, Russia
}

\begin{abstract}
The reciprocal motions at the vibrational separating machines of the sieving trunks, transmitted from the actuating mechanism, vibrate frame. The Frame weaving is put over the sieving trunks weaving, disturbing the optimal mode of operation. Therefore, for the bearing structures of separating machines vibration decrease it is necessary to optimize its structures and characteristics of the actuating mechanism, which would provide the minimal mass with the necessarily frame rigidity.
\end{abstract}

\section{Introduction}

The Vibrational machines are commonly used in different technical spheres for the granular blends separation on the heterogeneous fractions. Granular blends dosing, its mixing and Compaction.

On the vibrational machines technological process stable behavior is determined by the kinematic regime of the movable operating elements precise adherence. This factor assumes defining significance at the separating processes.

The reciprocal motions at the vibrational separating machines of the sieving trunks, transmitted from the actuating mechanism, vibrate frame. Frame weaving is put over the sieving trunks weaving, disturbing the optimal mode of operation. Therefore, for the bearing structures of separating machines vibration decrease it is necessary to optimize it structures and characteristics of the actuating mechanism, which would provide the minimal mass with the necessarily frame rigidity. Metal consumption of the building structures, on which such machines are installed, would depend on, in its turn, this parameter.

In connection to this, the optimal order of the constructs should be determined within the designing.

ºrresponding author: pivenvv@yandex.ru 


\section{Materials and method}

Consider the following case, when elements - horizontal, upstanding or bias Figure 1 are added for the increase of the frame structures rigidity. On their example, it is possible to work out the frame structures' optimization methodology, which is sustaining the vibrational strain. Current indexes of parameters 11 and 12 should be determined in the process of the optimization.

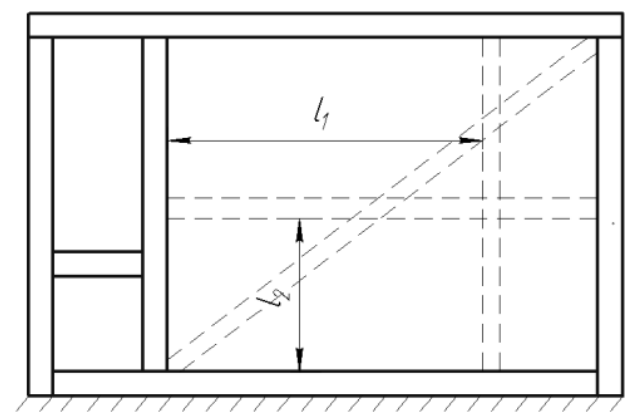

Fig. 1. The scheme of the frame structure with the elements provided its rigidity.

In the sequel, the usage of such approach will allow to optimize the rigidity of any construction of such type within the devised methodology. Thereby, the decompositional scheme of the mathematic model of the vibrational frame motion and the optimization of such a model has a view illustrated on the Fig. 2. It is necessary to explain the objective function during the mathematic modeling, to choose the limitations, imposed on the mathematical model; the power factors of the statically indeterminate frame, of actuating mechanism details must be defined; to specify the risky section's voltage, to state the bearing structure details' the vibration of displacement, the vibration velocity and the vibration acceleration.

The mass of the frame structure should be reasonably accepted as an objective function, this mass would be the function from the moment of the structure's beam inertia of section. The limitations must be imposed on this function: on the structural strength, on the permissible vibration of displacement, on technological process quality. The obtained scheme would allow optimizing the bearing structures of the vibrational separating machines, taking limitations by vibrocharacteristics into account at the stage of design.

By the example of the separating vibrational machine the methodology of the bearing frame structures of the vibrational machines optimization were worked out for the optimization the bearing frame structure rigidity (Figure 2).

The design parameters of the structure itself, kinematic parameters of the actuating mechanism are taken into consideration within this methodology with the help of the theoretical relations (Figure 3), these parameters influence the bearing structure vibrocharacteristics.

The methodology allows taking into account influence on the additional elements of rigidity of the vibrocharacteristics, to define its suitability installation and its seat.

In the first stage it is necessary to state dynamic forces on the actuating mechanism details for the foregoing methodology realization. Let's consider the disturbing influences character on the frame structure from the actuating mechanism on the example of the graincleaning machine with the crank-and-rod mechanism. Machine has two sieving trunks, which are moved towards each other. The complication of such task is concluded on that the sieving trunks reciprocal motions are necessary for the separation of the grains blend technological process realization. 
At the same time the sieving trunks actuating mechanism is the source of the frame structure itself forced oscillations. The frame structure vibrational movements are transmitted to the sieving trunks through the suspension arm mechanism, and they are influenced on the separated components movement process over the sieve. Separation is realized in nonoptimal regime, which is in whole led to the technological separation process quality decrease.

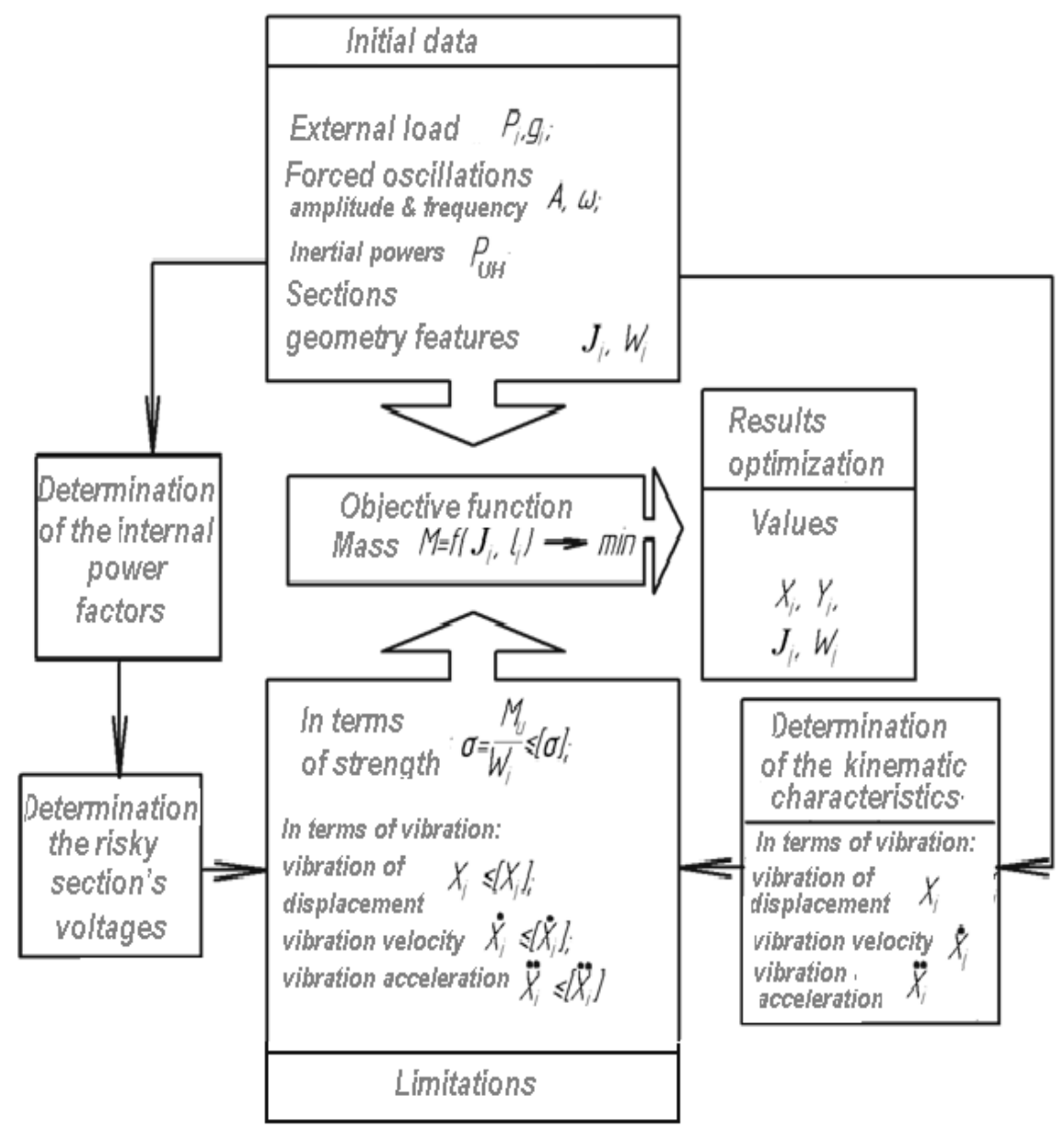

Fig. 2. Decompositional scheme of mathematical model of bearing structure vibrational movement optimization. 


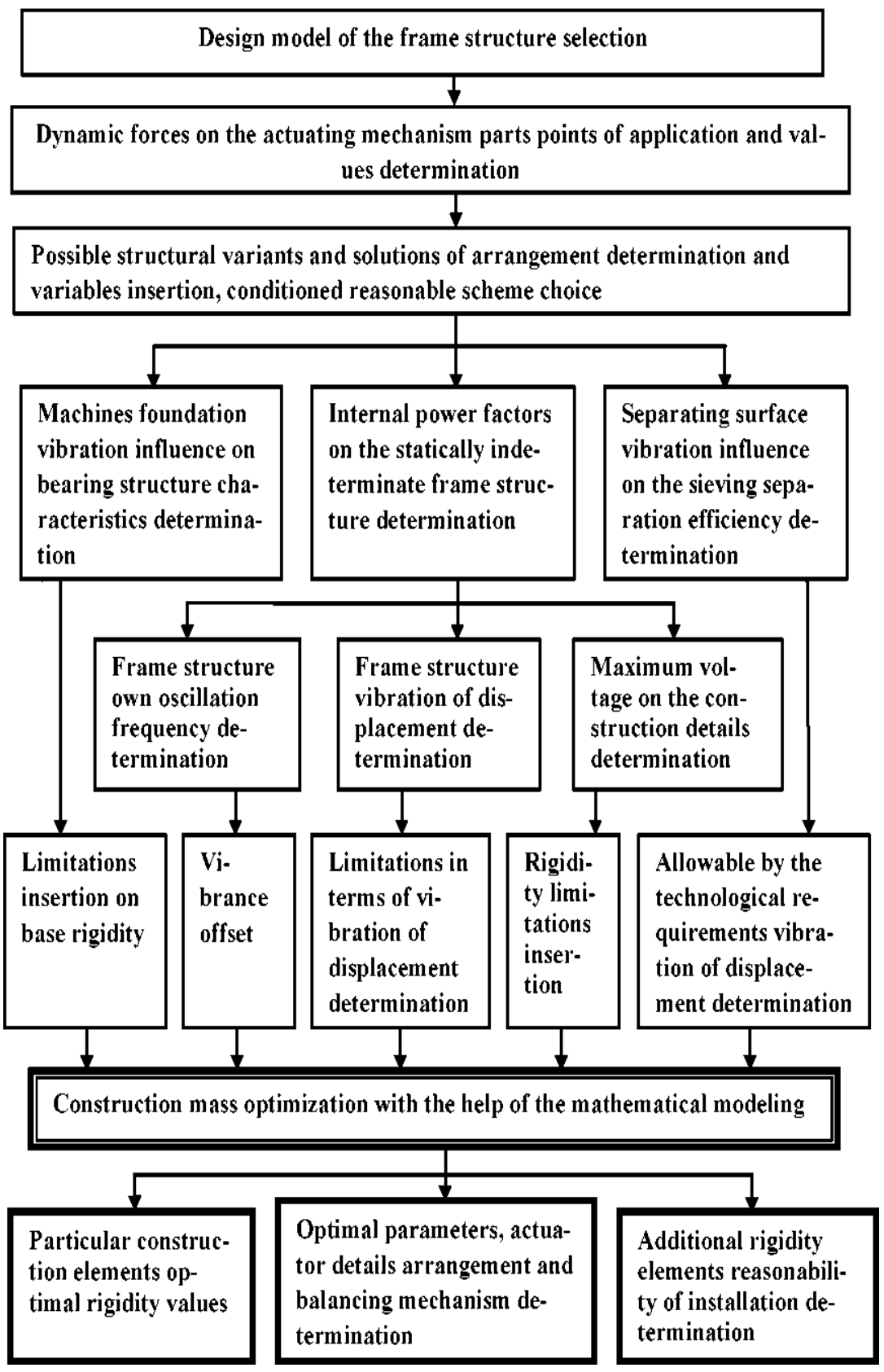

Fig. 3. Structural scheme of the calculating methodology of vibrational machines bearing frame constructions.

Review the bearing frame structure, represented in the Figure 4. The following systems of powers are actuated on the lower sieving trunk on it's the last right position (Figure 5). Examine the reactions, which are occurred at the A and B points in detail. The arm suspensions, made of plywood or steel, are used on the grain-cleaner machines for the rectilinear oscillations transition. In this case let's consider the plywood arm suspensions. Arm suspensions length $-0,53$ м. Section $-0,06 \times 0,01$ м. Separation trunk oscillation amplitude is the maximum bending at the arm suspension end. 


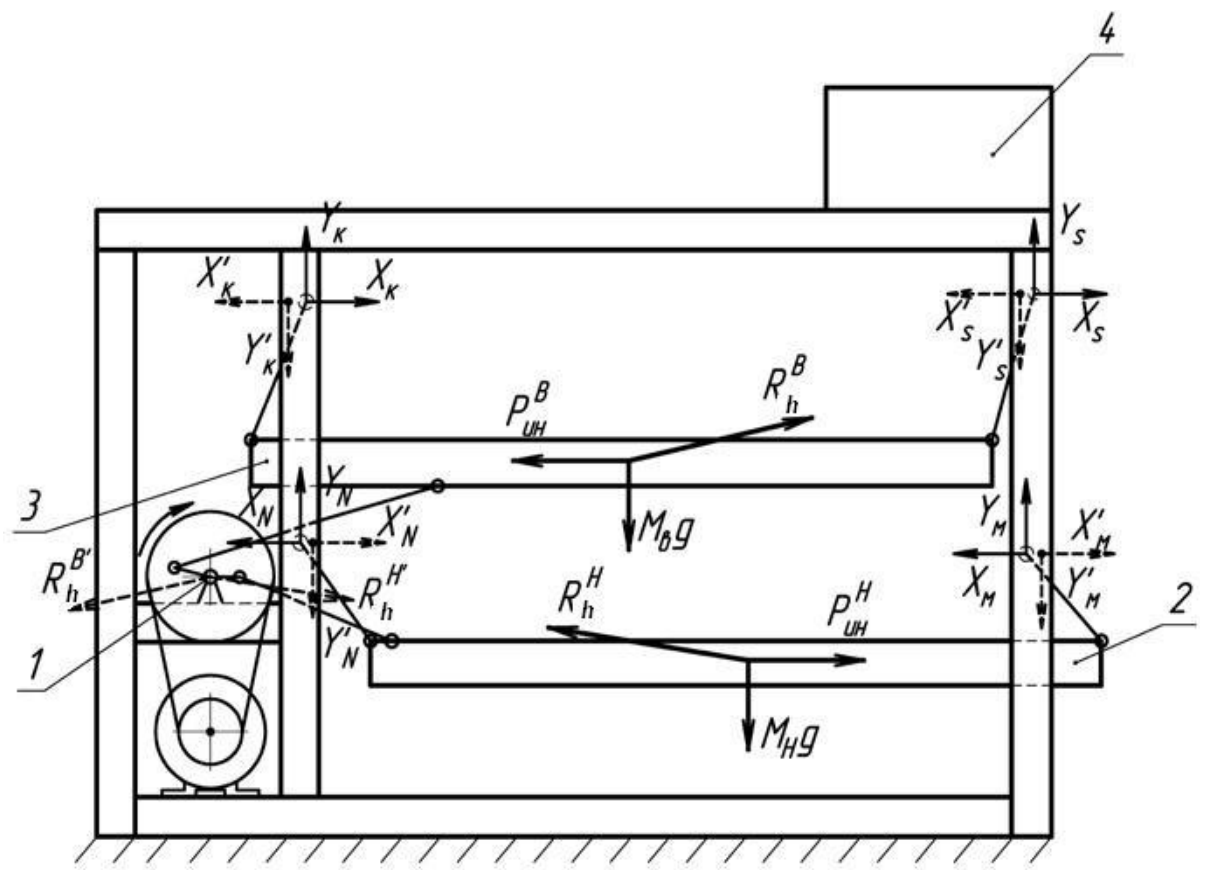

Fig. 4. Separation machine construction scheme (powers, actuating on the bearing structure from the side of the actuating mechanism details are pictured by doted line): 1 - actuating mechanism; 2 lower sieving trunk; 3- upper sieving trunk; 4 - aspiration system.

The suspension arm reactions are directed along it. Calculations show that the connectingrod reactive torque considerably lower than the other power factors. It is possible to ignore it.

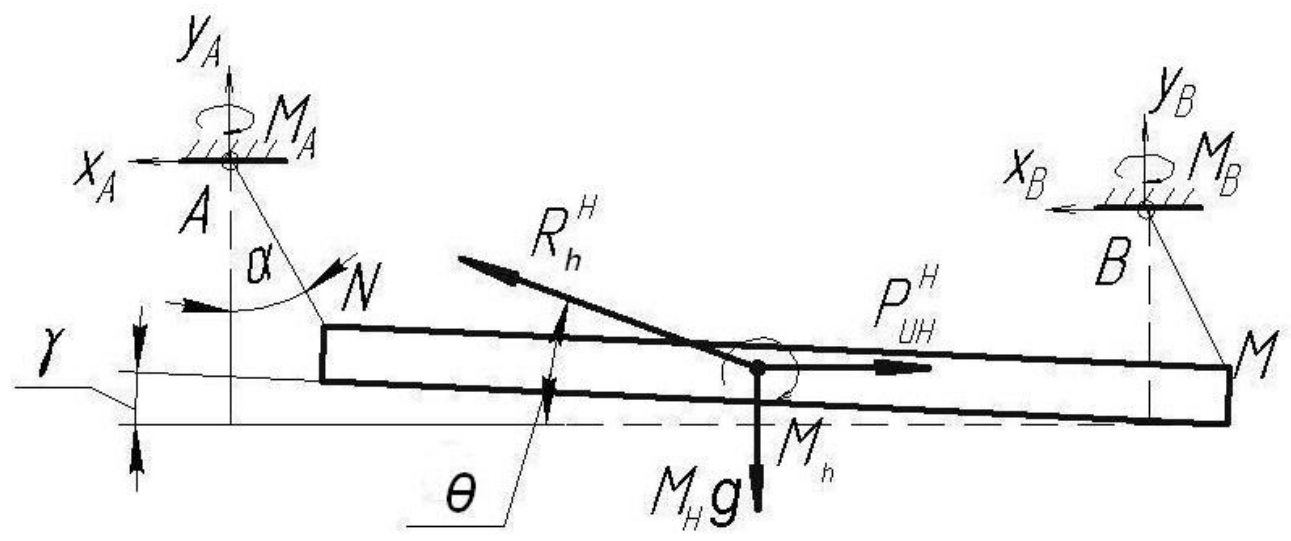

Fig. 5. Scheme of powers, actuating on the lower sieving trunk with suspension arms $M_{H q}$ - gravity; $P_{U H}{ }^{H}$ - inertial force; $M, R^{H}$ - connecting-rod reactions; $X_{A}, Y_{A}, M_{A}, X_{B}, Y_{B}, M_{B}$ - reactions at the suspension restraint point. (points. A and B).

Hereby, taking into account foregoing allowance, the scheme of powers, actuating on the lower sieving trunk, has the following view (Figure 6): 


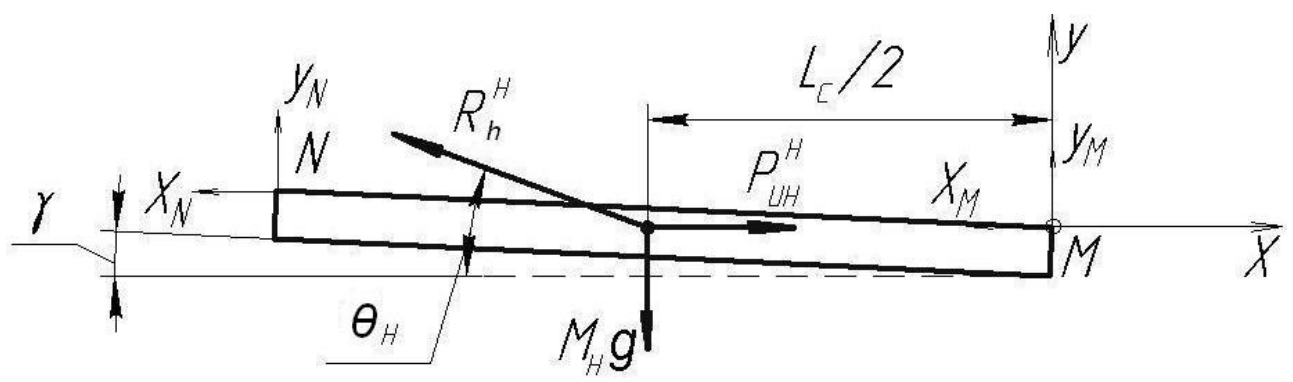

Fig. 6. Scheme of powers, actuating on the lower sieving trunk.

Make up the balance equation for the flat powers system in order to determine the reaction on the points $\mathrm{N}$ and $\mathrm{M}$.

$$
\begin{gathered}
\sum F_{k x}:-x_{N}-R^{n} \cdot \cos \theta_{u}+P-x=0 \\
\sum F_{k y}: y_{N}+R \cdot \sin \theta_{u}-M_{u} \cdot g+y_{M}=0 \\
\sum M_{M}\left(\bar{F}_{k}\right): x_{N} \cdot L_{c} \cdot \sin \gamma-y_{N} \cdot L_{c} \cdot \cos \gamma-R^{u} \cdot \sin \theta_{u} \frac{L_{c}}{2} \cdot \cos \gamma+ \\
+R \cdot \cos \theta_{u} \frac{L_{c}}{2} \cdot \sin \gamma+M_{n} \cdot g \cdot \frac{L_{c}}{2} \cdot \cos \gamma-P^{u} \cdot \frac{L_{c}}{2} \cdot \sin \gamma=0 .
\end{gathered}
$$

Inertia $P_{\text {ин }}^{\mathrm{H}}$ is determined by the formula:

$$
P_{\mathrm{u}}^{\mathrm{H}}=M_{\mathrm{H}} \cdot a
$$

Where: $M_{H}$ - the lower sieving trunk mass $(\mathrm{kg})$, a - acceleration of masses center of the lower sieving trunk $\left(\mathrm{m} / \mathrm{sec}^{2}\right)$

We are used the following relation to determine the acceleration [1]:

$$
a=\ddot{x}=r \omega^{2}\left(\cos \omega \cdot t-\frac{e}{L} \sin \omega \cdot t\right)
$$

Where $\mathrm{r}$ - crank radius $(\mathrm{m}), \omega$ - crank angular velocity $(\mathrm{rad} / \mathrm{s}), \mathrm{t}-$ time $(\mathrm{s}), \mathrm{e}-$ desaxial displacement value $(\mathrm{M}), \mathrm{L}-$ crank length $(\mathrm{M})$.

Taking into account, that $\mathrm{M}_{\mathrm{A}}=0, \mathrm{M}_{\mathrm{B}}=0$ (Figure 5) and the suspension arm reaction is directed along it, get

$$
\begin{aligned}
& x_{N}=y_{n} \cdot \operatorname{tg} \alpha \\
& x_{M}=y_{M} \cdot \operatorname{tg} \alpha
\end{aligned}
$$

Angle $\alpha$ is varied according to the principle:

$$
\operatorname{tg} \alpha=\frac{r}{L_{n}} \cdot \cos \omega \cdot t
$$

Taking into account the formulas (6) - (8) the powers at the points $\mathrm{N}$ and $\mathrm{M}$ would be determined by the following formulas: 


$$
\begin{aligned}
& x_{N}=y_{n} \cdot \frac{r}{L_{n}} \cdot \cos \omega \cdot t \\
& x_{M}=y_{M} \cdot \frac{r}{L_{n}} \cdot \cos \omega \cdot t
\end{aligned}
$$

Take the following designation: $\mathrm{R}^{\mathrm{H}}=\mathrm{R}_{1} ; \mathrm{M}_{\mathrm{N}}=\mathrm{M}_{2} ; \mathrm{L}_{\mathrm{C}}=\mathrm{L}_{1} ; \mathrm{L}=\mathrm{L}_{2} ; \mathrm{L}_{\mathrm{n}}=\mathrm{L}_{3}$.

Taking into account the obtained formulas and entering designations the equations system (1) shall have the following view:

$$
\begin{gathered}
-x_{N}-R_{1} \cdot \cos \theta_{H}+M_{2} \cdot x-x_{M}=0 \\
y_{N}+R_{1} \cdot \sin \theta_{u}-M_{2} \cdot g+y_{M}=0 \\
x_{N} \cdot L_{1} \cdot \sin \gamma-y_{N} \cdot L_{1} \cdot \cos \gamma-R_{1} \cdot \sin \theta_{u} \frac{L_{1}}{2} \cdot \cos \gamma+R_{1} \cdot \cos \theta_{H} \frac{L_{1}}{2} \cdot \sin \gamma+ \\
+M_{2} \cdot g \cdot \frac{L_{1}}{2} \cdot \cos \gamma-P_{1} \cdot \frac{L_{1}}{2} \cdot \sin \gamma=0 . \\
x_{N}=y_{n} \cdot \frac{r}{L_{n}} \cdot \cos \omega \cdot t \\
x_{M}=y_{M} \cdot \frac{r}{L_{n}} \cdot \cos \omega \cdot t
\end{gathered}
$$

Solving this equation system relatively to the $\mathrm{x}_{\mathrm{N}}, \mathrm{x}_{\mathrm{M}}, \mathrm{y}_{\mathrm{N}}, \mathrm{y}_{\mathrm{M}}$ and $\mathrm{R}_{1}$, will get:

$$
\begin{gathered}
R_{1}=\frac{M_{2} \cdot g \frac{r}{L_{3}} \cdot \cos \omega \cdot t-M_{2} r \omega^{2}\left(\cos \omega \cdot t-\frac{e}{L_{2}} \cdot \sin \omega \cdot t\right)}{\sin \theta_{H} \cdot \frac{r}{L_{3}} \cos \omega \cdot t-\cos \theta_{H}} \\
y_{N}=\frac{R_{1}\left(\sin \theta_{H} \cdot \cos \gamma+\cos \theta_{H} \cdot \sin \gamma\right)-M_{2} \mathrm{~g} \cos \gamma+M_{2} r \cdot \omega^{2}\left(\cos \omega \cdot t-\frac{e}{L_{2}} \cdot \sin \omega \cdot t\right) \sin \gamma}{2 \cdot\left(\frac{r}{L_{3}} \cdot \cos \omega \cdot t \cdot \sin \gamma-\cos \gamma\right)} \\
x_{N}=y_{n} \cdot \frac{r}{L_{n}} \cdot \cos \omega \cdot t \\
x_{M}=x_{N}
\end{gathered}
$$




\section{Results and discussion}

Solving this equations, relatively to the time and cranks angular velocity, will get the following values $x_{N}, x_{M}, y_{N}, y_{M}$ and $R_{1}$, when $e=6,5 \cdot 10^{-2} \mathrm{M} ; \mathrm{r}=7,5 \cdot 10^{-3} \mathrm{M} ; \mathrm{L}_{1}=1,723 \mathrm{~m}$; $\mathrm{L}_{2}=0,5 \mathrm{M} ; \quad \mathrm{L}_{3}=0,53 \mathrm{M}$ :

$$
\begin{gathered}
x_{N}=-1,217+11,513 \cdot \cos \omega t+1,605 \cdot 10^{-4} \cdot \sin \omega t-1,217 \cdot \cos 2 \omega t+0,16 \cdot \sin 2 \omega t \\
y_{N}=813,5-171,966 \cdot \cos \omega t+22,562 \cdot \sin \omega t-0,171 \cdot \cos 2 \omega t+0,023 \cdot \sin 2 \omega t
\end{gathered}
$$

$$
R_{1}=\frac{2,5 \cdot 103 \cdot \cos \omega \mathrm{t}-329 \sin \omega \mathrm{t}}{1,013-2,017 \cdot 10^{-3} \cos \omega \mathrm{t}}
$$

The last right position of the lower sieving trunk corresponds to the last left position of the upper sieving trunk (Figure 7).

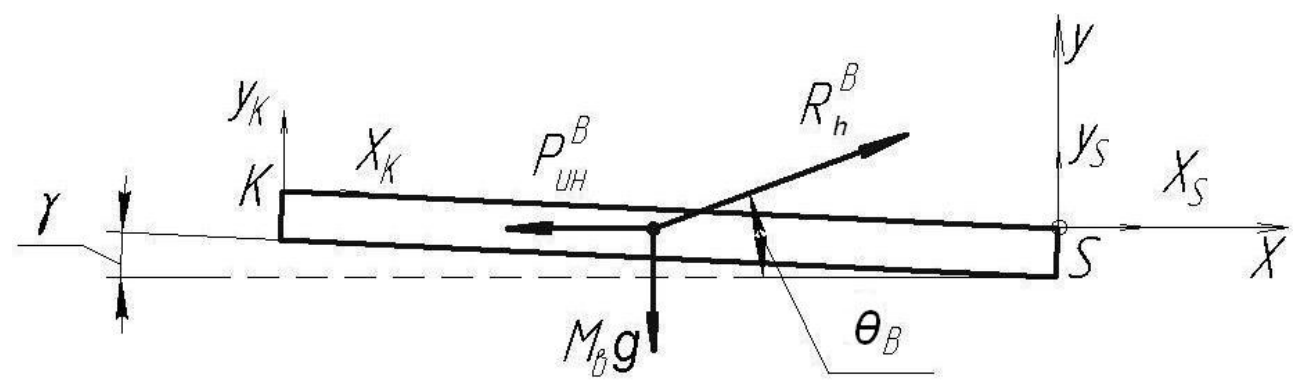

Fig. 7. The scheme of the powers, actuating on the upper sieving trunk.

The balance equation of the upper sieving trunk has the view:

$$
\begin{gathered}
\sum F_{k x}: x_{K}+R^{\beta} \cdot \cos \theta-P+x_{S}=0 \\
\sum F_{k y}: y_{K}+R^{b} \cdot \sin \theta-M \cdot \mathrm{g}+y_{S}=0 \\
\sum M_{S}\left(\bar{F}_{k}\right):-y_{K} \cdot L_{c} \cdot \cos \gamma-x_{K} \cdot L_{c} \cdot \sin \gamma-R^{\beta} \cdot \cos \theta \frac{L_{c}}{2} \cdot \sin \gamma- \\
-R \cdot \sin \theta \frac{L_{c}}{2} \cdot \cos \gamma+M \cdot \mathrm{g} \cdot \frac{L_{c}}{2} \cdot \cos \gamma+P_{u h}^{\beta} \cdot \frac{L_{c}}{2} \cdot \sin \gamma=0 .
\end{gathered}
$$

Taking into account, that

$$
\begin{gathered}
\operatorname{tg} \alpha=\frac{r}{L_{n}} \cdot \cos \omega t \\
x_{k}=y_{k} \cdot \operatorname{tg} \alpha=y_{k} \cdot \frac{r}{L_{n}} \cdot \cos \omega t \\
x_{s}=y_{s} \cdot \operatorname{tg} \alpha=y_{s} \cdot \frac{r}{L_{n}} \cdot \cos \omega t
\end{gathered}
$$




$$
P=M b \cdot r \cdot \omega^{2}\left(\cos \omega \cdot t-\frac{e}{L} \cdot \sin \omega \cdot t\right)
$$

And entering the following designations: $\mathrm{R}=\mathrm{R}_{2} ; \mathrm{M}_{\mathrm{B}}=\mathrm{M}_{1} ; \mathrm{L}_{\mathrm{C}}=\mathrm{L}_{1} ; \mathrm{L}_{\mathrm{n}}=\mathrm{L}_{3}$, will get the balance equations system for the upper sieving trunk:

$$
\begin{gathered}
x_{K}+R_{2} \cdot \cos \theta+x_{S}-M_{1} \cdot r \cdot \omega^{2}\left(\cos \omega \cdot t-\frac{e}{L} \cdot \sin \omega \cdot t\right)=0 \\
y_{K}+R_{2} \cdot \sin \theta-M_{1} \cdot g+y_{S}=0 \\
-y_{K} \cdot L_{1} \cdot \cos \gamma-x_{K} \cdot L_{1} \cdot \sin \gamma+M_{1} \cdot \frac{L_{1}}{2} \cdot \sin \gamma \cdot r \cdot \omega^{2}\left(\cos \omega \cdot t-\frac{e}{L} \cdot \sin \omega \cdot t\right)- \\
-R_{2} \cdot \cos \theta \frac{L_{1}}{2} \cdot \sin \gamma-R_{2} \cdot \sin \theta_{6} \frac{L_{1}}{2} \cdot \cos \gamma+M_{1} \cdot q \cdot \frac{L_{1}}{2} \cdot \cos \gamma=0 . \\
x_{k}=y_{k} \cdot \operatorname{tg} \alpha=y_{k} \cdot \frac{r}{L_{n}} \cdot \cos \omega t \\
x_{s}=y_{s} \cdot \operatorname{tg} \alpha=y_{s} \cdot \frac{r}{L_{n}} \cdot \cos \omega t
\end{gathered}
$$

Solving this system relatively to the $\mathrm{x}_{\mathrm{S}}, \mathrm{x}_{\mathrm{K}}, \mathrm{y}_{\mathrm{S}}, \mathrm{y}_{\mathrm{K}}$ and $\mathrm{R}_{2}$, will get the following values unknown power factors:

$$
\begin{gathered}
R_{2}=\frac{-M_{1} \cdot g \frac{r}{L_{3}} \cdot \cos \omega \cdot t+M_{1} r \omega^{2}\left(\cos \omega \cdot t-\frac{e}{L_{2}} \cdot \sin \omega \cdot t\right)}{-\sin \theta_{B} \cdot \frac{r}{L_{3}} \cos \omega \cdot t+\cos \theta_{B}} \\
y_{K}=\frac{-R_{2}\left(\sin \theta_{B} \cdot \cos \gamma+\cos \theta_{B} \cdot \sin \gamma\right)+M_{1} g \cos \gamma+M_{1} r \cdot \omega^{2}\left(\cos \omega \cdot t-\frac{e}{L_{2}} \cdot \sin \omega \cdot t\right) \sin \gamma}{2\left(\frac{r}{L_{3}} \cdot \cos \omega \cdot t \cdot \sin \gamma-\cos \gamma\right)} \\
y_{K}=y_{S} \\
x_{k} \cdot y_{k}=y_{k} \cdot \frac{r}{L_{n}} \cdot \cos \omega t \\
x_{k}=x_{S}
\end{gathered}
$$

Solving this equations relatively to the time and crank angular velocity, will get the following values $\mathrm{x}_{\mathrm{K}}, \mathrm{x}_{\mathrm{S}}, \mathrm{y}_{\mathrm{K}}, \mathrm{y}_{\mathrm{S}}$ and $\mathrm{R}_{2}$ : 


$$
\begin{gathered}
x_{k}=-1,103+10,435 \cdot \cos \omega t+1,436 \cdot 10-4 \cdot \sin \omega t-1,103 \cdot \cos 2 \omega t+0,145 \\
\cdot \sin 2 \omega t
\end{gathered}
$$

$$
\begin{gathered}
y_{k}=734,5-155,928 \cdot \cos \omega t+20,465 \cdot \sin \omega t-0,155 \cdot \cos 2 \omega t+0,02 \\
\cdot \sin 2 \omega t
\end{gathered}
$$

$$
R_{2}=\frac{2,76 \cdot 10^{3} \cdot \cos \omega \cdot t-331,87 \sin \omega \cdot t}{1,237-0,2 \cdot 10^{-2} \cos \omega \cdot t}
$$

Thus, the power factors relations are received $x_{N}, x_{M}, x_{K}, x_{S}, y_{N}, y_{M}, y_{K}, y_{S}, R_{2}$ and $R_{1}$ from the disturbing power frequency and the time. Taking into account, that the suspensions reactions are directed along these suspensions, we shall get the following scheme of disturbing powers application to the frame. (Figure 8).

Reactions components from the connecting rod on the point $\mathrm{O}$ we can present as:

$$
\begin{aligned}
& x_{0}=R_{1} \cdot \cos \theta_{H}-R_{2} \cdot \cos \theta \\
& y_{0}=-R_{1} \cdot \sin \theta_{H}-R_{2} \cdot \sin \theta
\end{aligned}
$$

Will determine the values $x_{0}$ and $y_{0}$ depending on the time and crank angular velocity.

$$
\begin{gathered}
x_{0}=0,228+229,451 \cdot \cos \omega t-30,1 \cdot \sin \omega t+0,228 \cdot \cos 2 \omega t-0,03 \cdot \sin 2 \omega t \\
y_{0}=-0,652-656,049 \cdot \cos \omega t+86,088 \cdot \sin \omega t-0,652 \cdot \cos 2 \omega t+0,086 \cdot \sin 2 \omega t
\end{gathered}
$$

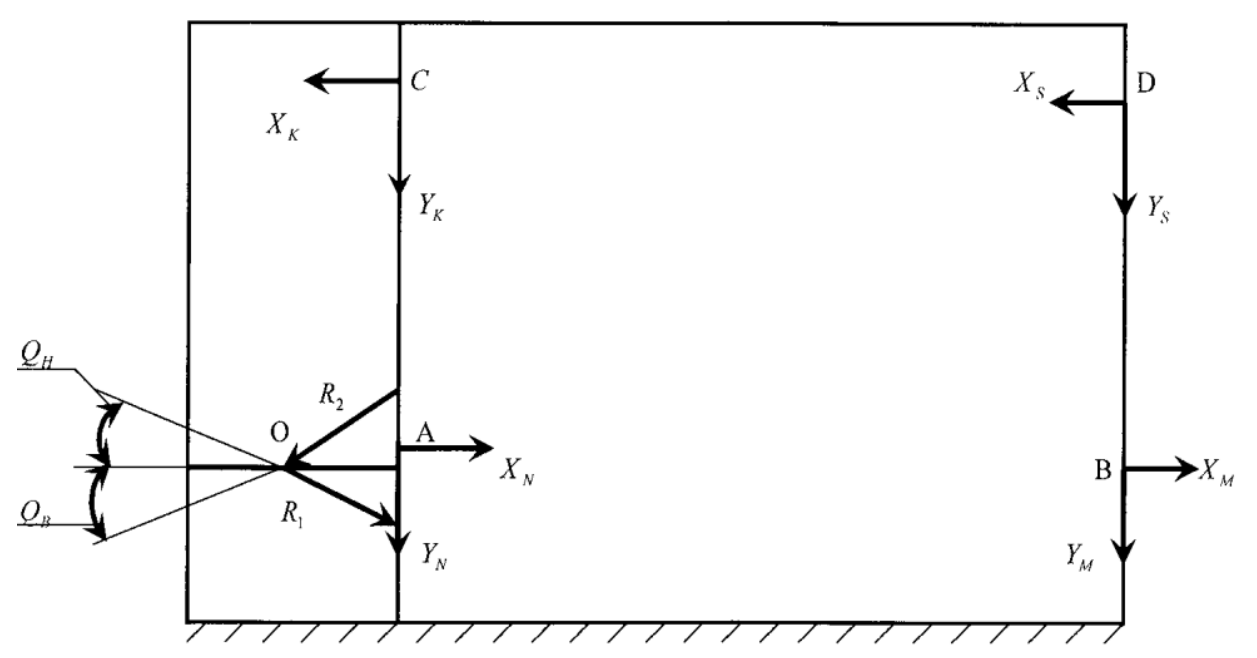

Fig. 8. The scheme of disturbing forces to the bearing structure elements application. 


\section{Conclusion}

The analysis of the equations (41), (42), (46) and (47) shows, that the coefficients of connecting-rods reactions periodic functions considerably exceed the corresponding coefficients at the formulas of the suspension arms reactions determination. Therefore, connecting-rod reactions would effect by means of disturbing influence to the bearing structure.

The obtained simplified formulas (41), (42), (46) and (47) for the dynamic forces on the vibrational separating machine actuating mechanism details determination are the one of the stage of realization of the device methodology of such machines constructions optimization.

\section{References}

1. V. G. Chumakov V. G.,Tractors and Agricultural Machinery, 12 (2011)

2. N. M. Ivanov, N. P. Lapshin, International Research Journal, 10-2(41) (2015)

3. N. P. Lapshin, International Research Journal, 28-30 (2016)

4. V. V. Piven, O. L. Umanskaya, Modern scientific researches and innovations, 3 (2013)

5. V. V. Piven, O. L. Umanskaya, Russian Engineering Research, 27 (2007)

6. V. V. Piven, O. L. Umanskaya, Modern scientific researches and innovations, 3 (2014) 